\title{
Fatigue Life Improvement of Cracked Aluminum 6061-T6 Plates Repaired by Composite Patches
}

\author{
Armin Yousefi $^{1,2}\left(\mathbb{D}\right.$, Saman Jolaiy $^{2}$, Reza Hedayati $^{3}{ }^{(0)}$, Ahmad Serjouei $^{1}\left(\mathbb{D}\right.$ and Mahdi Bodaghi ${ }^{1, *}(\mathbb{C}$ \\ 1 Department of Engineering, School of Science and Technology, Nottingham Trent University, \\ Nottingham NG11 8NS, UK; yousefi.armin@ut.ac.ir (A.Y.); ahmad.serjouei@ntu.ac.uk (A.S.) \\ 2 School of Mechanical Engineering, College of Engineering, University of Tehran, \\ P.O. Box, Tehran 11155-4563, Iran; samanjolaiy@ut.ac.ir \\ 3 Department of Aerospace Structures and Materials, Faculty of Aerospace Engineering, Delft University of \\ Technology (TU Delft), Kluyverweg 1, 2629 HS Delft, The Netherlands; rezahedayati@gmail.com \\ * Correspondence: mahdi.bodaghi@ntu.ac.uk
}

Citation: Yousefi, A.; Jolaiy, S.;

Hedayati, R.; Serjouei, A.; Bodaghi, M. Fatigue Life Improvement of Cracked Aluminum 6061-T6 Plates Repaired by Composite Patches. Materials 2021, 14, 1421. https://doi.org/10.3390/ ma14061421

Academic Editor: Davide Palumbo

Received: 23 February 2021

Accepted: 12 March 2021

Published: 15 March 2021

Publisher's Note: MDPI stays neutral with regard to jurisdictional claims in published maps and institutional affiliations.

Copyright: (C) 2021 by the authors. Licensee MDPI, Basel, Switzerland. This article is an open access article distributed under the terms and conditions of the Creative Commons Attribution (CC BY) license (https:/ / creativecommons.org/licenses/by/ $4.0 /)$.

\begin{abstract}
Bonded patches are widely used in several industry sectors for repairing damaged plates, cracks in metallic structures, and reinforcement of damaged structures. Composite patches have optimal properties such as high strength-to-weight ratio, easiness in being applied, and high flexibility. Due to recent rapid growth in the aerospace industry, analyses of adhesively bonded patches applicable to repairing cracked structures have become of great significance. In the present study, the fatigue behavior of the aluminum alloy, repaired by a double-sided glass/epoxy composite patch, is studied numerically. More specifically, the effect of applying a double-sided composite patch on the fatigue life improvement of a damaged aluminum 6061-T6 is analyzed. 3D finite element numerical modeling is performed to analyze the fatigue performance of both repaired and unrepaired aluminum plates using the Abaqus package. To determine the fatigue life of the aluminum 6061-T6 plate, first, the hysteresis loop is determined, and afterward, the plastic strain amplitude is calculated. Finally, by using the Coffin-Manson equation, fatigue life is predicted and validated against the available experimental data from the literature. Results reveal that composite patches increase the fatigue life of cracked structures significantly, ranging from $55 \%$ to $100 \%$ for different applied stresses.
\end{abstract}

Keywords: aluminum 6061-T6; composite patch; finite element modeling; plasticity; fatigue life

\section{Introduction}

Nowadays, composite patches, due to their unique properties such as lightness, ease of application, high flexibility, and high stiffness, are increasingly being used in industrial applications such as aerospace structures and automobile industries. Investigation of the tensile strength and fatigue behavior of aluminum alloys is still capturing the attention of researchers. Traditional methods of repairing aluminum alloys, for instance, mechanical fastening, could lead to new defects. Composite patches, unlike traditional methods, do not cause any damage to the parent plate and can be replaced several times [1-6]. Fiber-reinforced polymer composites are the right choice for being used as a patch since these materials have a high stiffness-to-weight ratio, good fatigue resistance, and excellent corrosion resistance [7-10].

Using composite patches for repairing structures was first introduced by Baker et al. [11] in the early 1970s in Australia for military aircraft. Afterward, this technology was implemented for repairing structures in the aerospace and automobile industries [12]. Several researchers have analyzed the repairing efficiency of composite patches and have done several optimization analyses on the patch design. Seo et al. [13] investigated the fatigue crack growth in thick aluminum plates repaired by a composite patch. They conducted an experimental study for $10 \mathrm{~mm}$ thick specimens repaired by graphite/epoxy patches. The stress intensity factor was determined by both experimental test and finite element 
method (FEM), and the results were compared. Ergun et al. [14] examined the fatigue life of damaged aluminum 2024-T3 reinforced by composite patches under the hygrothermal effect. The effect of patch thickness and humidity was analyzed. The results revealed that the numbers of patch layers and hygrothermal conditions significantly affect fatigue life.

The FEM is an excellent technique to analyze the effect of different repair process parameters on the overall performance of structures repaired by polymer composite patches $[8,9,14-19]$. Calculating stress intensity factor (SIF) is a reliable approach to describing crack growth behavior $[15,17,19-21]$. Ouinas et al. [15] studied the effect of the patch geometry and adhesive properties on the efficiency of the repair process. They calculated the stress intensity factor using finite element (FE) models. The results indicated that increasing the patch diameter reduces the SIF. Adhesive properties also have a significant effect on the repair output. Toudeshky et al. [16] investigated the residual thermal stresses in structures repaired by a composite patch. Using numerical and experimental approaches, they examined the effect of thermal expansion coefficient mismatch, which leads to residual thermal stresses on the crack-front shape. Results indicated that the thermal residual stresses did not affect the stress intensity factor at the crack-front in the aluminum 2024-T3 plate repaired by patch. Albedah et al. [17] analyzed patch dimensions' influence on the efficiency of overall patch performance numerically and experimentally for aluminum 2024-T3 and aluminum 7075-T6. 3D FEM was performed to calculate the SIF to evaluate the patch's effectiveness. Results indicated that increasing the patch length leads to decreasing the fatigue life of repaired plates. Dai et al. [8] studied the effects of resin properties and composite patch configurations on the repair process of the damaged aluminum alloy plates. FEM and experimental studies were carried out to examine the failure of the repaired structures under tensile loadings. Observation revealed that damage was initiated in the layers adjacent to the crack surface. Moreover, delamination and fiber breakage is the main reason for the failure of the composite patch. Mohammadi [18] investigated the effect of different parameters such as the thickness of a cracked plate on the performance and durability of a one-sided composite patch repairing process. Results indicated that the efficiency of the repair process firmly depends upon the parent plate thickness and patch material. Yousefi et al. [19] studied the effect of composite and nanocomposite patch volume fraction on the performance of the repair process. They examined the impact of the patch and adhesive thickness on the efficiency of the repair process. 3D FE analysis was carried out to determine the SIF. Results indicated that SIF significantly depends on the patch stiffness. Hosseini et al. [22] investigated the fatigue behavior of cracked aluminum 1050 repaired by glass/epoxy patches numerically and experimentally for different stress ratios ranging between 0 to 1 . Results indicated that by employing the double-sided composite patch, fatigue life is improved significantly for stress ratios 0 and 0.5. Khan Mohammad et al. [23] examined the effect of different shapes of composite patches on the efficiency of the repair process experimentally and numerically. Both numerical and experimental studies showed that composite shape has a significant effect on the repair performance, and rectangular patches provide the most efficient repair compared to the triangular shape. Recent studies show that several parameters could affect the fatigue life improvement, such as the minimization of stress concentration, which improves fatigue life, and environmental condition also may influence the fatigue life [24,25]. Most of the previous research studies have investigated the effect of composite patch on the crack growth or fatigue life by calculating SIF by employing FEM. However, to the authors's best knowledge, no research work has been carried out on determining the fatigue life of damaged aluminium plates repaired by composite patches employing a strain-based approach.

In the present study, the effect of applying double-sided glass fiber/epoxy composite on the fatigue life improvement of cracked aluminum 6061-T6 plate is investigated numerically. 3D finite element analysis is performed to investigate the effect of glass fiber/epoxy patch on the fatigue life of damaged structures. In this regard, the steady-state hysteresis loop is determined, from which the plastic strain is calculated. It is worth mentioning that since the strain-based approach is based on the plastic strain, to gain more reliable results 
and calculate strain, the cylindrical volume (part) as representative volume element is considered near the crack zone in which the strain is calculated by volume averaging of strain from all elements in this specified cylindrical-shaped volume. To the best of the authors' knowledge, no research work uses this approach (volume averaging) to calculate the strain considering the strain-based approach. Finally, the fatigue life of different configurations (undamaged plate, unrepaired damaged plate, and repaired damaged plate) is predicted. Therefore, the main novelty of this study is employing the strain-based approach to investigate the effect of applying glass fiber/epoxy composite patch on fatigue life in which the strain is calculated using representative volume element (cylindrical-shaped volume).

\section{Materials and Models}

The centrally cracked aluminum 6061-T6 plate (subjected to rolling process) with an initial crack length of $\mathrm{a}=2 \mathrm{~mm}$ repaired by the composite patches is illustrated in Figure 1 . The length (2L), width $(2 w)$, and thickness (2t) of the aluminum plate are $500 \mathrm{~mm}, 125 \mathrm{~mm}$, and $12.5 \mathrm{~mm}$, respectively. As shown in Figure 1a, the crack (blue line) is in the plate's center and perpendicular to the applied load. The patch is bonded to the cracked plate by means of Araldite 2015 (Huntsman Corporation, The Woodlands, TX, USA) [26]. The initial mechanical properties of the plate and adhesive are listed in Table 1. The Johnson-Cook material model [27] was used to model the elastic-plastic behavior of the aluminum plate. This material model is implemented to model material behavior in large deformations, and it considers the isotropic hardening characteristic. In this study, since the structures undergo large deformation extents, the Johnson-Cook material model is employed. The Johnson-Cook constants for Al6061-T6 (Aluminum Alloys) [28] are listed in Table 2. The mechanical properties of glass fiber/epoxy composite patch are extracted from the work of Devireddy et al. [29], which is reported in Table 3.

Table 1. Mechanical properties of aluminum plate and adhesive [26,30].

\begin{tabular}{ccccc}
\hline Materials & Materials Behavior & Elastic Modulus (MPa) & Poisson's Ratio & Tensile Strength (MPa) \\
\hline Araldite 2015 & elastic isotropic & 1850 & 0.33 & 21.63 \\
\hline Aluminum 6061-T6 & elastic-plastic & 72,000 & 0.35 & 311 \\
\hline
\end{tabular}

Table 2. The Johnson-Cook model constants for Al6061-T6 [28].

\begin{tabular}{cccccc}
\hline A (MPa) & B (MPa) & $\mathbf{C}_{\mathbf{0}}$ & $\mathbf{n}$ & $\mathbf{m}_{\mathbf{0}}$ & \\
\hline 250 & 79.7 & 0.0249 & 0.499 & 1.499 & \\
\hline
\end{tabular}

Table 3. Mechanical properties of glass fiber/epoxy composite patch [29].

\begin{tabular}{ccccccccccc}
\hline & Fiber Volume Fraction (\%) & $\mathrm{E}_{\mathbf{1}}(\mathrm{GPa})$ & $\mathrm{E}_{2}(\mathrm{GPa})$ & $\mathrm{E}_{3}(\mathrm{GPa})$ & $\mathrm{V}_{12}$ & $\mathrm{~V}_{13}$ & $\mathrm{~V}_{23}$ & $\mathrm{G}_{12}(\mathrm{GPa})$ & $\mathrm{G}_{13}(\mathrm{GPa})$ & $\mathrm{G}_{23}(\mathrm{GPa})$ \\
\hline Glass Fiber /Epoxy & 60 & 45 & 12 & 12 & 0.28 & 0.28 & 0.4 & 5 & 5 & 5.6 \\
\hline
\end{tabular}

\subsection{Numerical Modeling}

The cracked aluminum 6061-T6 plate under cyclic loading was analyzed by employing Abaqus software (V. 6.14, Dassault Systems, France). Figure 2 illustrates a typical 3D FE model of a cracked aluminum plate repaired by a composite patch. The FE model consists of three parts: the cracked aluminum plate, the adhesive layer, and the patches. The contact between the patch-adhesive interface and the adhesive-plate interface is assumed to be a perfect bond. The perfect bond is applied using Tie constraint in Abaqus software. The perfect bond is used to define surface-to-surface contact interaction in which the rotational and translational motion is equal between two connected surfaces. Figure 3 shows a discretized model of the repaired aluminum plate containing a surface crack. In order to discretize the repaired plate, the plate was sectioned into three parts using the Partition tool in Abaqus software. 3D 8-node linear hexahedral elements of type C3D8R were used 
to mesh the areas far away from the crack, while 10-node tetrahedral elements of type C3D10 were used to mesh the area in the neighborhood of the crack (cylindrical-shaped volume). To obtain more accurate results, the element size around the cracked region was smaller than the element size of the area far away from the crack. Eight-node linear wedge cohesive elements of type COH3D6 are utilized to mesh the adhesive parts. Also, linear tetrahedral elements of type C3D4 were used to mesh the patch. The boundary conditions applied on the structures that stimulate a relevant fatigue test are reported in Table 4 . In this study, to examine the effect of patches on fatigue life improvement at different stress amplitudes, different cyclic displacements were applied.
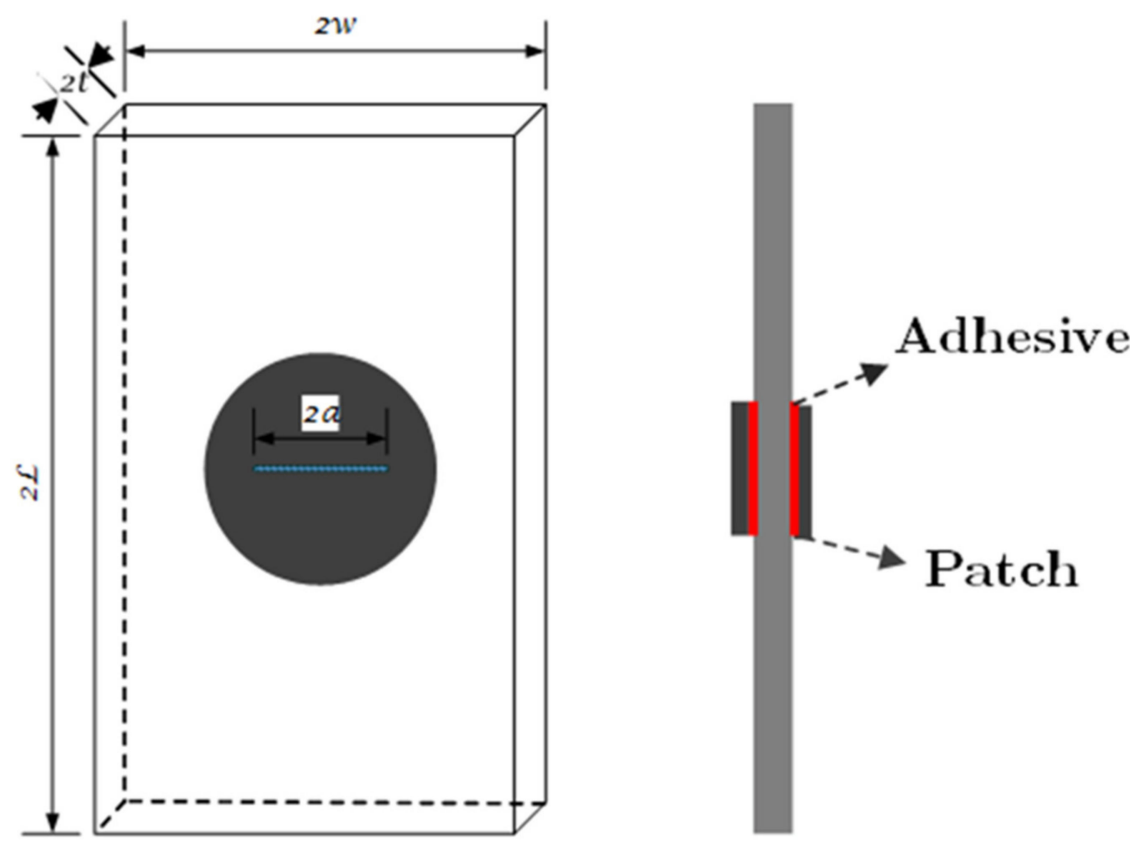

(a)

\section{Composite Patch}

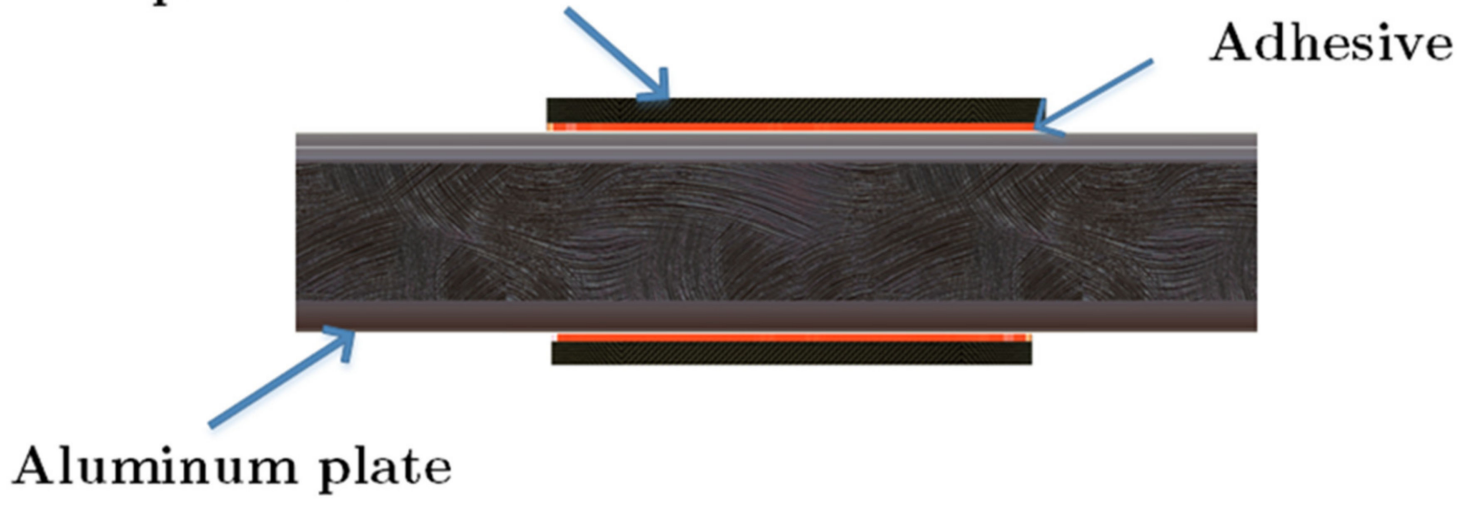

(b)

Figure 1. Geometry of repaired damaged aluminum plate: (a) Perspective view and (b) Front view. 


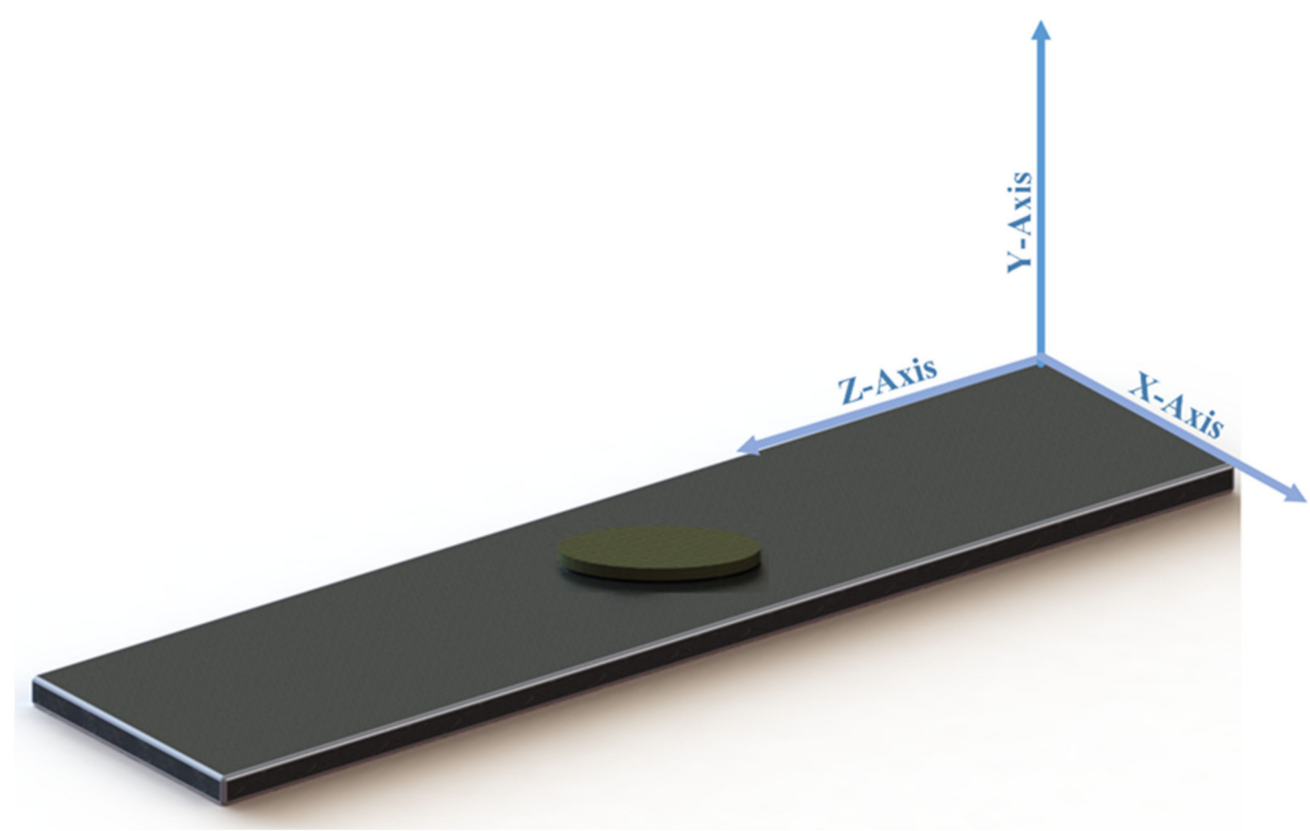

Figure 2. FE model of cracked aluminum plate repaired by composite patches.

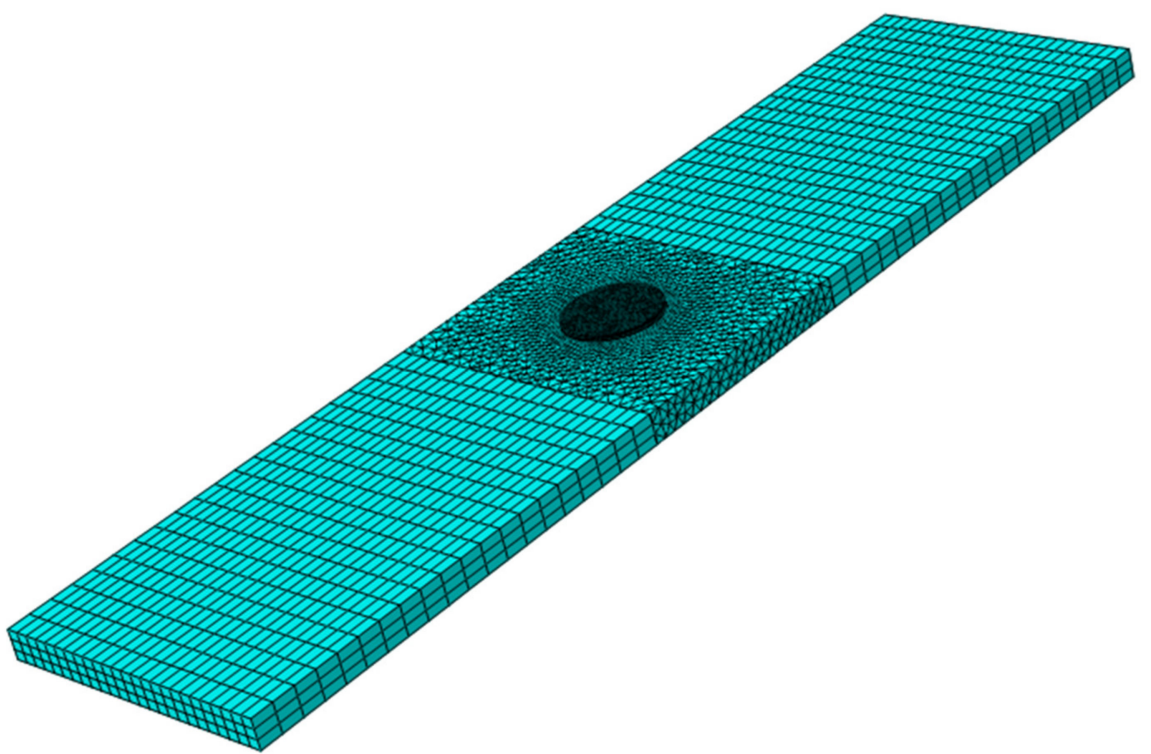

Figure 3. A discretized model of the repaired aluminum plate containing a surface crack.

Table 4 . The boundary conditions applied to the structure.

\begin{tabular}{ccccc}
\hline Plane & $\mathbf{Z}=\mathbf{0}$ & $\mathbf{Y}=\mathbf{0}$ & $\mathbf{X}=\mathbf{0}$ & $\mathbf{Z}=\mathbf{2 L}$ \\
\hline Boundary Condition & $\mathrm{Uz}=0$ & $\mathrm{Uy}=0$ & $\mathrm{Ux}=0$ & $\mathrm{Uz}=$ cyclic displacement \\
\hline
\end{tabular}

In the present study, mesh independence analysis was also performed. For this aim, the element size was reduced (in other words, the number of elements was increased) systematically until the resulting engineering stress-strain curves converged to the same amount. As indicated in Figure 4, the stress-strain curves of the repaired plate converged for element numbers between 120,000 and 160,000. Therefore, in the present study, the element numbers implemented are at least 160,000 . 


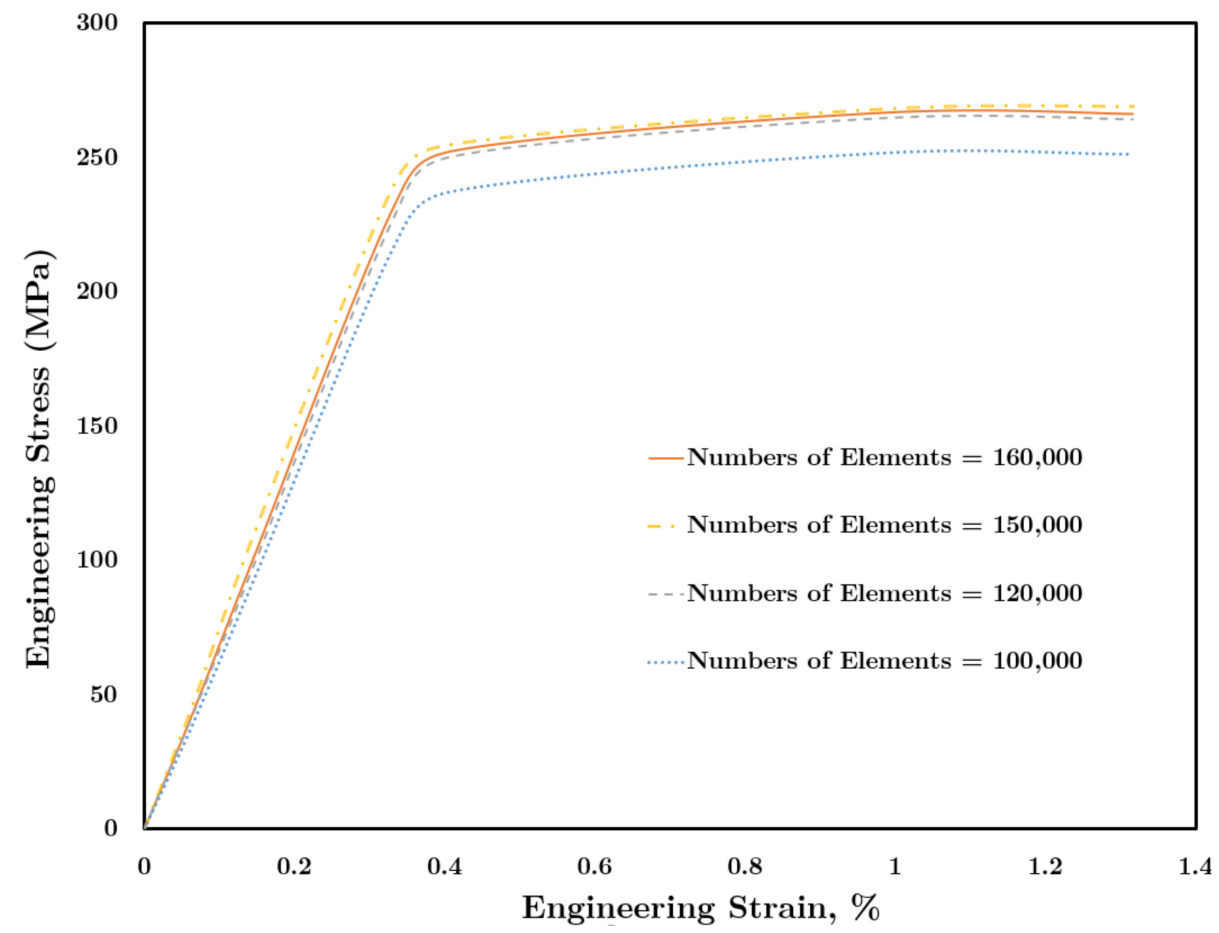

Figure 4. Effect of the number of elements on the engineering stress-strain curve.

\subsection{Fatigue Life Analysis}

In the present study, in order to determine the fatigue life, the strain-based approach was employed. In this regard, the stress-strain hysteresis loop was plotted. The total strain amplitude was determined, which was divided into two components, elastic strain and plastic strain [31]. By considering the hysteresis loop, the plastic strain can be determined by obtaining the intercept of the loop curve on the strain axis. The stress-life curve could be linearized on the log scale. The curve is described by:

$$
\sigma_{a}=\sigma_{f}\left(2 N_{f}\right)^{b}
$$

where $2 N_{f}$ is the number of life cycles until failure, $\hat{\sigma}_{f}$ is the fatigue strength coefficient, and $b$ is the fatigue strength exponent. Coffin and Manson [31] found the strain-life data could also be linearized on the log scale and be expressed as:

$$
\frac{\Delta \varepsilon_{\text {ave }-p}}{2}=\hat{\varepsilon}_{f}\left(2 N_{f}\right)^{c}
$$

where $\Delta \varepsilon_{a v e-p} / 2$ is the volume averaging plastic strain amplitude, $\varepsilon_{f}$ is the fatigue ductility coefficient, and $c$ is the fatigue ductility exponent.

It is worth mentioning that in order to calculate the strain, the homogenized variables (strain) are determined by volume averaging from all elements in the cylindrical-shaped volume around the crack. This specified volume has a diameter equal to the patch's diameter; the height equals the plate thickness, and the crack is exactly in the center of this cylinder. The total strain is calculated as:

$$
\varepsilon_{\text {ave }}=\frac{1}{V_{m}} \int \varepsilon_{m} d V
$$

In Equation (3), $\varepsilon_{\text {ave }}$ is volume averaging total strain (consist of elastic and plastic strain), $\varepsilon_{\mathrm{m}}$ is the local strain in each element, and $V_{m}$ is the total volume of the specified cylindrical-shape part. After calculating volume averaging total strain by Equation (3), 
the steady-state hysteresis loop is plotted for different conditions in Abaqus software, the volume averaging plastic strain amplitude is determined.

In the next step, to predict the fatigue life, Equation (2) was implemented, so the number of cycles to failure was calculated using a MATLAB (MathWorks, Natick, MA, USA) code based on the Newton-Raphson method. The material constants in Equations (1) and (2) are reported in Table 5 [32].

Table 5. Materials parameters for aluminum 6061-T6 [32].

\begin{tabular}{cc}
\hline Materials Constant & Aluminum 6061-T6 \\
\hline Fatigue Ductility Coefficient, $\dot{\varepsilon}_{f}(\mathrm{~mm} / \mathrm{mm})$ & 0.77 \\
\hline Fatigue Ductility Exponent, $c$ & -1.01 \\
\hline Fatigue Strength Coefficient, $\dot{\sigma}_{f}(\mathrm{MPa})$ & 386 \\
\hline Fatigue Strength Exponent, $b$ & -0.036 \\
\hline
\end{tabular}

\section{Results}

\subsection{Validation}

To verify the proposed model, FEM results were compared with available experimental data [33]. In order to validate the proposed model in the present study, the dimensions of the aluminum plate for comparison of FEM results with experimental data were chosen based on fatigue test standard reported in Ref. [33]. Figure 5 compares the FEM results of the fatigue life for the undamaged aluminum 6061-T6 plate for different stress amplitude against the available experimental data [33]. As shown in Figure 5, there is a good agreement between experimental data and FEM results. The maximum differences between experimental and FEM results are about $20 \%$, although, at a stress amplitude of $140 \mathrm{MPa}$, this difference is less than $3 \%$. It should be mentioned that at stress amplitude of $\Delta \sigma / 2=260 \mathrm{MPa}$, there is about a $23 \%$ difference in the numbers of cycles to failure reported by the experimental study. Therefore, these differences between the proposed model and experimental data (ranging from $3 \%$ to $20 \%$ ) could be acceptable for the proposed model in the present study.

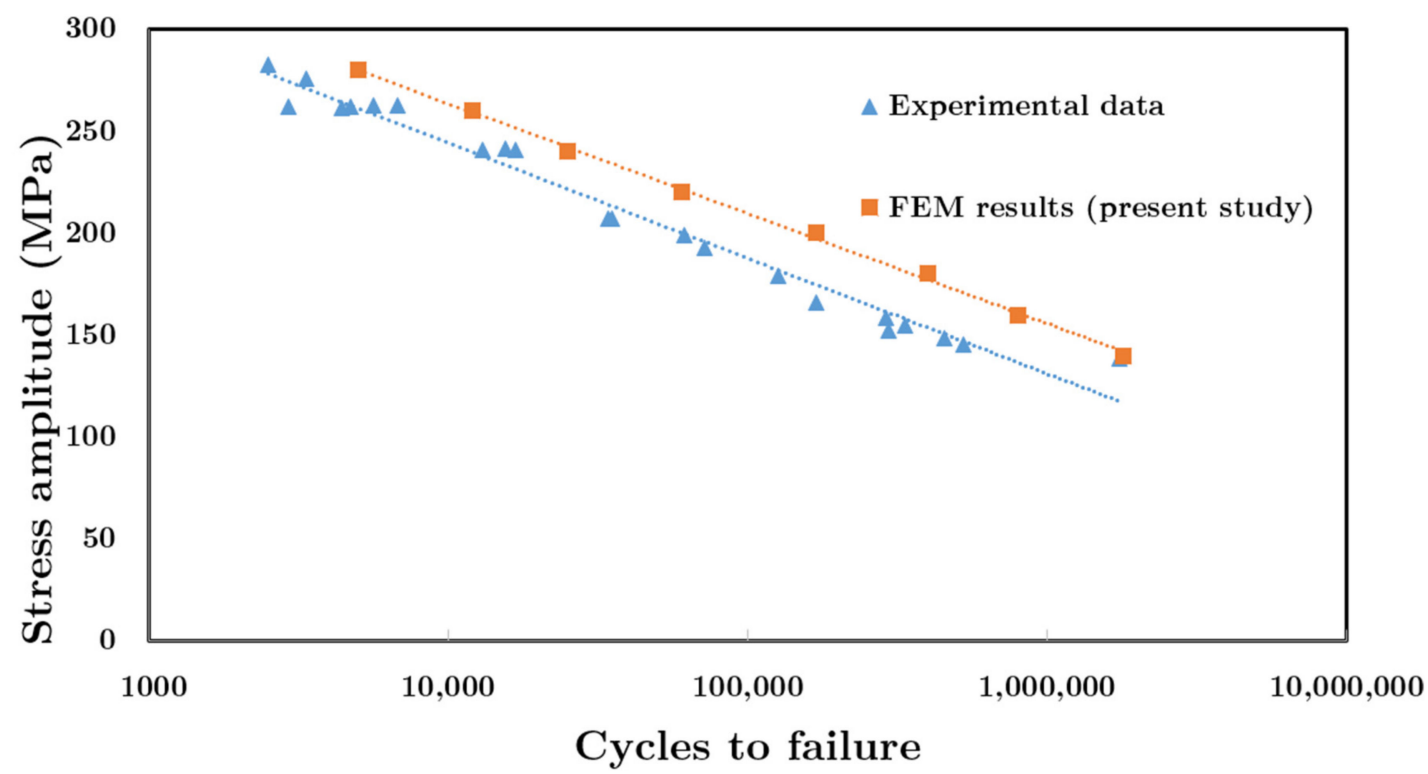

Figure 5. Stress amplitude versus cycles for undamaged aluminum 6061-T6 for both FEM in the present study and experimental data [33]. 


\subsection{Hysteresis Loop}

Figure 6 shows a typical hysteresis loop for three types of aluminum plates, namely unrepaired damaged aluminum plate, repaired damaged aluminum plate, and the undamaged plate.

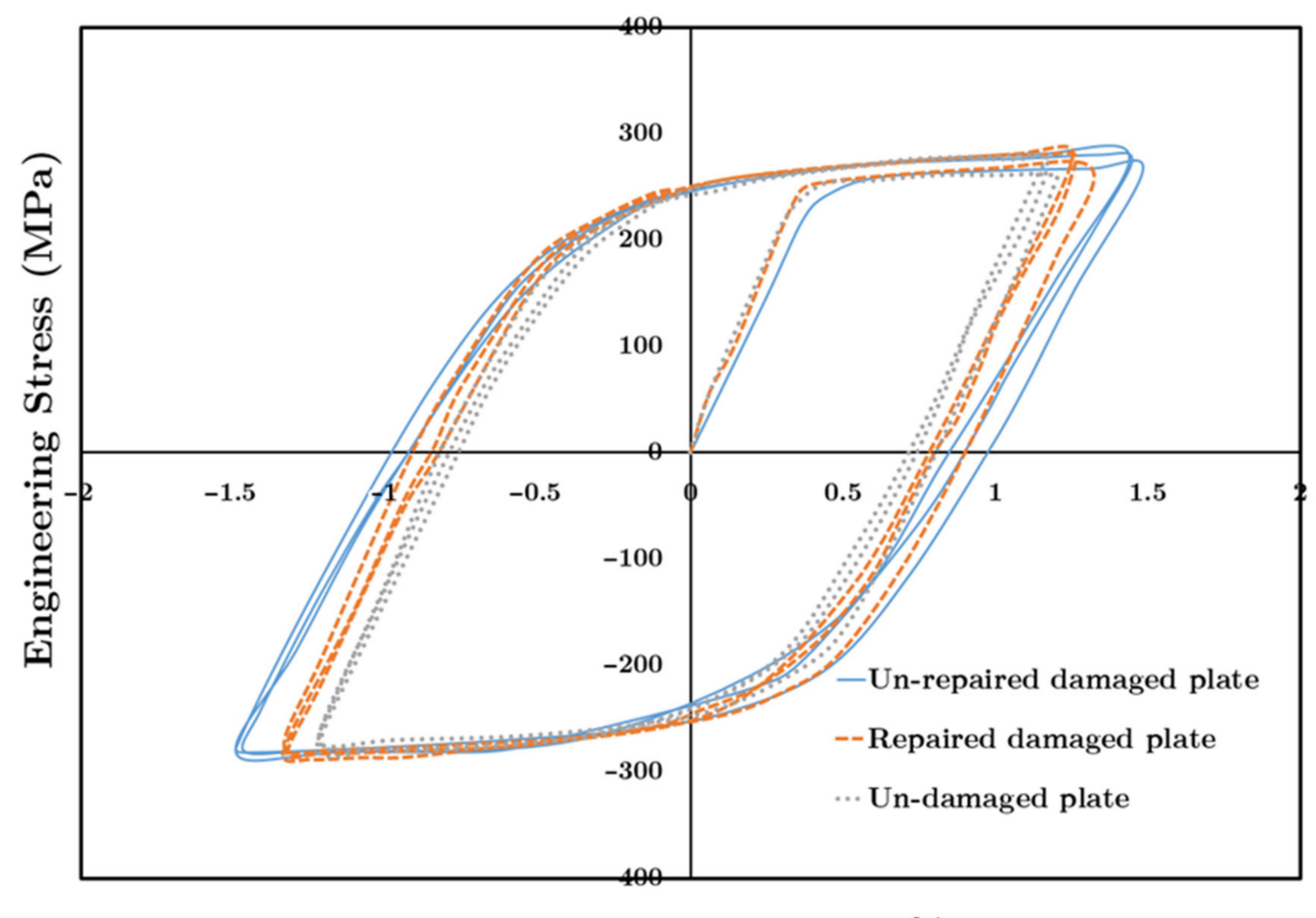

Engineering Strain, \%

Figure 6. Hysteresis loop for different plate conditions.

The stress-strain hysteresis loop is drawn in Figure 6 for the fatigue loading condition of stress ratio of $\mathrm{R}=-1$, and stress amplitude of $\Delta \sigma / 2=280 \mathrm{MPa}$ is applied to all the cases. At $\sigma=0$, the total strain equals plastic strain. According to Equation (2), by increasing the plastic strain amplitude, the fatigue life decreases. Figure 6 shows that the undamaged plate has the lowest strain extent at $\sigma=0$, which equals plastic strain amplitude. Furthermore, the unrepaired damaged plate has the highest plastic strain amplitude. The strain extent of the curve of the repaired damaged plate lies in the area between the curves of the undamaged plate and the unrepaired damaged plate, which demonstrates the improvement that repairing the damaged plate has made.

\subsection{Fatigue Life Prediction}

As partially mentioned above, in order to predict the fatigue life of both the repaired and unrepaired cracked aluminum plates, first, the hysteresis loop is determined. In this regard, to calculate the hysteresis loop, stress amplitude (y-axis in Figure 7), the amount of stress in the area far from the crack area, is calculated. However, the strain is calculated in the specified cylindrical part. Therefore, at a stress amplitude of $150 \mathrm{MPa}$ (far from crack), the stresses in some elements in the cylindrical part reach yield stress, so plastic strain exists and is determined by Equation (3). Therefore, Equation (2), which is based on plastic strain amount, can be employed even though the stress far from the crack area does not reach the yield amount. The hysteresis loops for three cases (undamaged, damaged, and repaired damaged plate) at each specific stress amplitude are drawn. Afterward, the plastic strain amplitude is calculated based on drawn hysteresis loops for each plate and at each specific stress amplitudes. Finally, by using the Coffin-Manson equation, fatigue life is predicted. 


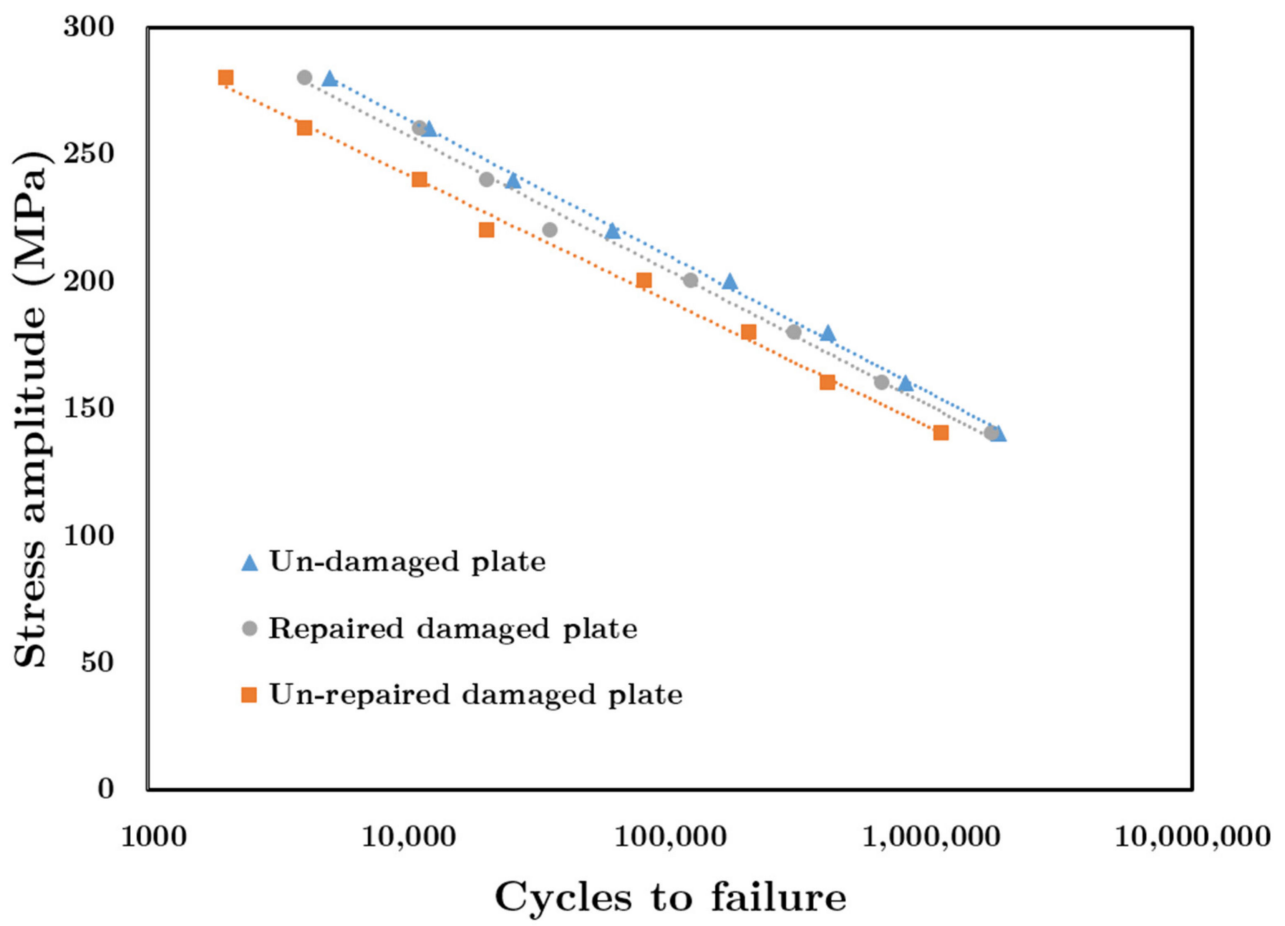

Figure 7. Stress amplitude versus fatigue life for different plate conditions.

Figure 7 compares the fatigue life of unrepaired and repaired aluminum plates to one another as well as to the fatigue life of the undamaged plate. Figure 7 is a semi-log graph in which the $x$-axis (cycle to failure) has a logarithmic scale. As shown in this figure, using a composite patch at high-stress amplitude is more effective on the increasing fatigue life as compared to when it is used in low-stress amplitude. At $\Delta \sigma / 2=280 \mathrm{MPa}$, applying a double-sided composite patch on the damaged aluminum plate increases the logarithmic fatigue life by almost $100 \%$. In comparison, at $\Delta \sigma / 2=140 \mathrm{MPa}$, applying a double-sided composite patch increases the logarithmic fatigue life by $55 \%$.

The main reason for the improvement of fatigue life is that by applying the composite patch at each applied stress amplitude (which is determined far away from the crack area), the stress in the area near the crack is decreased and is lower than the plate without the composite patch. Therefore, the amount of plastic strain is decreased, so according to Equation (2), the numbers of cycles to failure $\left(N_{f}\right)$ increases. In the higher applied stresses amplitude (for example, at $280 \mathrm{MPa}$ ), applying a composite patch could even have a more significant effect on reducing stress (as well as plastic strain) in the area near the crack in comparison to lower applied stresses (at $140 \mathrm{MPa}$ ). Therefore, at higher applied stress, the applied composite patch is more effective.

\section{Conclusions}

In the present study, the effects of applying a composite patch on the fatigue life of cracked aluminum plates were studied numerically. In this regard, the stress-strain hysteresis loops were drawn for three specimens: cracked aluminum plate, repaired aluminum plate, and undamaged aluminum plate. Based on the strain-based approach, the fatigue life was calculated for three types of specimens. The results showed that:

1. The aluminum plate repaired by composite patches has a narrower hysteresis loop in the strain direction compared to the unrepaired damaged plate. Therefore, the plastic strain amplitude of the repaired plate is lower than the unrepaired plate. For example, at $\Delta \sigma / 2=280 \mathrm{MPa}$, the plastic strain amplitude of the repaired plate becomes $50.3 \%$ less than the plastic strain amplitude of the unrepaired damaged plate.

2. Using the composite patch improves the logarithmic fatigue life significantly (at $\Delta \sigma / 2=280 \mathrm{MPa}$, by $100 \%$ and at $\Delta \sigma / 2=140$, by $55 \%)$. 
3. The higher the applied load level, the higher the effect of applying a double-sided composite patch is on the damaged aluminum plate's fatigue life improvement.

In this paper, the modeled structure was composed of materials that are common materials used in industry. For instance, Araldite 2015 (Huntsman Corporation, The Woodlands, TX, USA) as an adhesive was employed and used for applying patches to the aluminum plate; in addition, glass fiber/epoxy composite was used as a patch, which is highly utilized in industry for repairing damaged structures. Furthermore, the results in the present study were compared with available experimental data to verify the proposed model. Therefore, the results reported in this article could be reliable and give new insight into the fatigue life improvement of the repaired aluminum plate by composite patches.

Author Contributions: Conceptualization, A.Y.; Simulations, data collection, validation and analysis, A.Y. and S.J.; Methodology and investigation, A.Y., S.J., R.H., A.S. and M.B.; Supervision and technical advice R.H., A.S. and M.B.; Writing—original draft, A.Y., S.J.—review \& editing, A.Y., S.J., R.H., A.S. and M.B.; Resources, funding acquisition and project administration, M.B. All authors have read and agreed to the published version of the manuscript.

Funding: This research received no external funding.

Institutional Review Board Statement: Not applicable.

Informed Consent Statement: Not applicable.

Data Availability Statement: Data is contained within the article.

Conflicts of Interest: The authors declare no conflict of interest.

\section{References}

1. Kumar, P.; Shinde, P.S.; Bhoyar, G. Fracture Toughness and Shear Strength of the Bonded Interface Between an Aluminium Alloy Skin and a FRP Patch. J. Inst. Eng. Ser. C 2018, 100, 779-789. [CrossRef]

2. Kwon, Y.; Hall, B. Analyses of cracks in thick stiffened plates repaired with single-sided composite patch. Compos. Struct. 2015, 119, 727-737. [CrossRef]

3. Kumar, S.A.; Rajesh, R.; Pugazhendhi, S. A review of stress concentration studies on fibre composite panels with holes/cutouts. Proc. Inst. Mech. Eng. Part L J. Mater. Des. Appl. 2020, 234, 1461-1472. [CrossRef]

4. Ayatollahi, M.; Hashemi, R. Mixed mode fracture in an inclined center crack repaired by composite patching. Compos. Struct. 2007, 81, 264-273. [CrossRef]

5. Ayatollahi, M.; Hashemi, R. Computation of stress intensity factors (KI, KII) and T-stress for cracks reinforced by composite patching. Compos. Struct. 2007, 78, 602-609. [CrossRef]

6. De Finis, R.; Palumbo, D.; Serio, L.M.; De Filippis, L.A.C.; Galietti, U. Correlation between Thermal Behaviour of AA5754-H111 during Fatigue Loading and Fatigue Strength at Fixed Number of Cycles. Materials 2018, 11, 719. [CrossRef] [PubMed]

7. Makwana, A.H.; Shaikh, A.A.; Bakare, A.K.; Chitturi, S. Investigation of patch hybridization effect on the composite patch repair of a cracked aluminum plate: A pragmatic approach. Mech. Adv. Mater. Struct. 2018, 26, 1458-1468. [CrossRef]

8. Dai, J.; Zhao, P.; Su, H.; Wang, Y. Mechanical Behavior of Single Patch Composite Repaired Al Alloy Plates: Experimental and Numerical Analysis. Materials 2020, 13, 2740. [CrossRef] [PubMed]

9. Liu, X.; Wu, J.; Xi, J.; Yu, Z. Bonded Repair Optimization of Cracked Aluminum Alloy Plate by Microwave Cured Carbon-Aramid Fiber/Epoxy Sandwich Composite Patch. Materials 2019, 12, 1655. [CrossRef]

10. Hedayati, R.; Khouzani, S.G.; Jahanbakhshi, M. Investigation of debonding propagation in aluminum/composite joints under fatigue loading. J. Adhes. Sci. Technol. 2015, 29, 59-73. [CrossRef]

11. Baker, A.A.; Rose, L.F.; Jones, R. Advances in the Bonded Composite Repair of Metallic Aircraft Structure; Elsevier: Amsterdam, The Netherlands, 2003.

12. Rasane, A.R.; Kumar, P.; Khond, M.P. Optimizing the size of a CFRP patch to repair a crack in a thin sheet. J. Adhes. 2016, 93, 1064-1080. [CrossRef]

13. Seo, D.-C.; Lee, J.-J. Fatigue crack growth behavior of cracked aluminum plate repaired with composite patch. Compos. Struct. 2002, 57, 323-330. [CrossRef]

14. Ergun, E.; Taşgetiren, S.; Topçu, M. Fatigue and fracture analysis of aluminum plate with composite patches under the hygrothermal effect. Compos. Struct. 2010, 92, 2622-2631. [CrossRef]

15. Ouinas, D.; Sahnoune, M.; Benderdouche, N.; Bouiadjra, B.B. Stress intensity factor analysis for notched cracked structure repaired by composite patching. Mater. Des. 2009, 30, 2302-2308. [CrossRef]

16. Hosseini-Toudeshky, H.; Sadighi, M.; Vojdani, A. Effects of curing thermal residual stresses on fatigue crack propagation of aluminum plates repaired by FML patches. Compos. Struct. 2013, 100, 154-162. [CrossRef] 
17. Albedah, A.; Mohammed, S.M.K.; Bouiadjra, B.B.; Bouiadjra, B.A.B.; Benyahia, F. Effect of the patch length on the effectiveness of one-sided bonded composite repair for aluminum panels. Int. J. Adhes. Adhes. 2018, 81, 83-89. [CrossRef]

18. Mohammadi, S. Parametric investigation of one-sided composite patch efficiency for repairing crack in mixed mode considering different thicknesses of the main plate. J. Compos. Mater. 2020, 54, 3067-3079. [CrossRef]

19. Yousefi, A.; Mashhadi, M.M.; Safarabadi, M. Numerical analysis of cracked aluminum plate repaired with multi-scale reinforcement composite patches. J. Compos. Mater. 2020, 54, 4341-4357. [CrossRef]

20. Palumbo, D.; De Finis, R.; Ancona, F.; Galietti, U. Damage monitoring in fracture mechanics by evaluation of the heat dissipated in the cyclic plastic zone ahead of the crack tip with thermal measurements. Eng. Fract. Mech. 2017, 181, 65-76. [CrossRef]

21. Ancona, F.; Palumbo, D.; De Finis, R.; Demelio, G.; Galietti, U. Automatic procedure for evaluating the Paris Law of martensitic and austenitic stainless steels by means of thermal methods. Eng. Fract. Mech. 2016, 163, 206-219. [CrossRef]

22. Hosseini, K.; Safarabadi, M.; Ganjiani, M.; Mohammadi, E. Experimental and numerical fatigue life study of cracked AL plates reinforced by glass/epoxy composite patches in different stress ratios. Mech. Based Des. Struct. Mach. 2020, 1-17. [CrossRef]

23. Mohammed, S.M.K.; Mhamdia, R.; Albedah, A.; Bouiadjra, B.A.B.; Bouiadjra, B.B.; Benyahia, F. Fatigue crack growth in aluminum panels repaired with different shapes of single-sided composite patches. Int. J. Adhes. Adhes. 2021, 105, 102781. [CrossRef]

24. Ferdous, W.; Manalo, A.; Peauril, J.; Salih, C.; Reddy, K.R.; Yu, P.; Schubel, P.; Heyer, T. Testing and modelling the fatigue behaviour of GFRP composites-Effect of stress level, stress concentration and frequency. Eng. Sci. Technol. Int. J. 2020, 23, 1223-1232. [CrossRef]

25. Ferdous, W.; Manalo, A.; Yu, P.; Salih, C.; Abousnina, R.; Heyer, T.; Schubel, P. Tensile Fatigue Behavior of Polyester and Vinyl Ester Based GFRP Laminates-A Comparative Evaluation. Polymers 2021, 13, 386. [CrossRef]

26. Fernandes, T.A.; Campilho, R.D.; Banea, M.D.; Da Silva, L.F.M. Adhesive Selection for Single Lap Bonded Joints: Experimentation and Advanced Techniques for Strength Prediction. J. Adhes. 2015, 91, 841-862. [CrossRef]

27. Johnson, G.R.; Cook, W.H. A constitutive model and data for metals subjected to large strains, high strain rates and high temperatures. In Proceedings of the 7th International Symposium on Ballistics, The Hague, The Netherlands, $19-21$ April 1983.

28. Akram, S.; Jaffery, S.H.I.; Khan, M.; Fahad, M.; Mubashar, A.; Ali, L. Numerical and experimental investigation of Johnson-Cook material models for aluminum (Al 6061-T6) alloy using orthogonal machining approach. Adv. Mech. Eng. 2018, 10, 1-14. [CrossRef]

29. Devireddy, S.B.R.; Biswas, S. Effect of Fiber Geometry and Representative Volume Element on Elastic and Thermal Properties of Unidirectional Fiber-Reinforced Composites. J. Compos. 2014, 2014, 1-12. [CrossRef]

30. Uematsu, Y.; Tokaji, K.; Tozaki, Y.; Nakashima, Y.; Shimizu, T. Fatigue behaviour of dissimilar friction stir spot welds between A6061-T6 and low carbon steel sheets welded by a scroll grooved tool without probe. Fatigue Fract. Eng. Mater. Struct. 2011, 34, 581-591. [CrossRef]

31. Fatemi, A.; Plaseied, A.; Khosrovaneh, A.; Tanner, D. Application of bi-linear log-log S-N model to strain-controlled fatigue data of aluminum alloys and its effect on life predictions. Int. J. Fatigue 2005, 27, 1040-1050. [CrossRef]

32. Badaruddin, M.; Supriadi, H. Low Cycle Fatigue Properties of Extruded 6061-T6 Aluminum Alloy. J. Physics: Conf. Ser. 2019, 1198, 032002. [CrossRef]

33. Scott-Emuakpor, O.; George, T.; Cross, C.; Shen, M.-H.H. Hysteresis-loop representation for strain energy calculation and fatigue assessment. J. Strain Anal. Eng. Des. 2010, 45, 275-282. [CrossRef] 